\section{Use of Intersimple Sequence Repeat Assay for Detection of DNA Polymorphism Induced by Gamma Rays in Curcuma alismatifolia}

\author{
Sima Taheri' ${ }^{1}$, Thohirah Lee Abdullah ${ }^{1}$, \\ and Nur Ashikin Psyquay Abdullah \\ Department of Crop Science, Faculty of Agriculture, University Putra \\ Malaysia, 43400 UPM, Serdang, Selangor, Malaysia
}

\section{Zaiton Ahmad \\ Agrotechnology \& Biosciences Division Malaysian Nuclear Agency, 43000 Bangi, Selangor, Malaysia}

Additional index words. Curcuma alismatifolia, DNA polymorphism, Gamma rays, ISSR

\begin{abstract}
In plant breeding programs with vegetatively propagated plants, induced mutations with low physiological effects and strong genetic effects are important approaches for broadening the genetic variation. In the present study, intersimple sequence repeat (ISSR) assays were used to identify DNA polymorphism among the mutant varieties of Curcuma alismatifolia (Chiang Mai Red, Sweet Pink, Kimono Pink) and one hybrid (Doi Tung 554) exposed to 0-, 10-, and 20-Gy optimum doses of acute gamma irradiation. To identify DNA polymorphism among the mutants (10 and $20 \mathrm{~Gy})$ and non-treated ( 0 Gy) samples through ISSR assay, a total of 25 random primers were screened and 14 gave reproducible polymorphic bands. The number of presumed alleles revealed by the ISSR analysis ranged from three to 19 alleles with mean values of $6.5,7.8$, and 9.2 alleles per locus for doses of 0 (control), 10, and $20 \mathrm{~Gy}$, respectively. The average effective number of alleles, Nei's gene diversity, Shannon's information index, and polymorphic information content (PIC) were 1.41 to $1.48,0.24$ to $0.33,0.35$ to 0.45 , and 0.21 to 0.25 for the three doses, respectively. Percentages of polymorphic loci for nonirradiated (0 Gy), $10 \mathrm{~Gy}$, and $20 \mathrm{~Gy}$ individual plants were $76.4 \%, 83.7 \%$, and $85.8 \%$, respectively, with an average of $81.9 \%$. Jaccard's genetic similarity coefficient varied from 0.19 to 1.0 indicating the level of genetic variation among the mutants studied. In terms of variety, the range of genetic variation $(0.27$ to 0.4$)$ among individuals of the Doi Tung population was more than that observed in the other three varieties. In a dendrogram constructed based on genetic similarity coefficients, the $44 C$. alismatifolia individual plants fell into seven major clusters at a coefficient level of 0.35 . The study revealed that DNA polymorphism detected by ISSR analysis offered a useful molecular marker for the identification of mutants in gamma radiation-treated plants. Additionally, this research demonstrated that the DNA of the hybrid (Doi Tung 554) showed a greater response in induced mutation compared with the other varieties.
\end{abstract}

Curcuma alismatifolia belongs to the Zingiberaceae family. It is native to Indochina (Burma, Cambodia, and Thailand) and is distributed in all regions of Thailand up to altitudes of $900 \mathrm{~m}$ above sea level. It is valued in the floriculture industry as a cut flower and potted plants and has become an important crop for breeding new varieties with novel or improved traits as a result of its high economic value as a tropical ornamental (Prathepha, 2000).

One method for obtaining new cultivars of ornamental plants is mutation breeding

Received for publication 16 July 2013. Accepted for publication 20 Sept. 2013.

Research supported by the Fundamental Research Grant Scheme (FRGS) under the Ministry of Higher Education of Malaysia.

${ }^{1}$ To whom reprint requests should be addressed; e-mailssima_taheri65@yahoo.com; thohirah@agri. upm.edu.my. chlorophyll mutation in leaves have been developed and released in different ornamentals. So far, gamma rays were used to develop $64 \%$ of the radiation-induced mutant varieties, whereas $22 \%$ of induced mutants were produced by X-rays (Ahloowalia et al., 2004; Shu and Lagoda, 2007). Novelty visible in any form is of high value in ornamental crops and hence mutation breeding has played a key role in the improvement of ornamental crops in general and C. alismatifolia in particular.

Molecular markers can reveal differences among irradiated and non-irradiated individual plants at the DNA level and thus provide a more direct, reliable, and efficient tool for germplasm conservation and management (Kumar et al., 2006). Several molecular markers such as the random amplified polymorphic DNA (RAPD) (Panda et al., 2007; Syamkumar and Sasikumar, 2007), ISSR (Singh et al., 2012; Taheri et al., 2012), simple sequence repeat (SSR) (Sigrist et al., 2011; Siju et al., 2010), and amplified fragment length polymorphic (AFLP) (Das et al., 2011) with different advantages having been used in genetic variation studies of Curcuma species. However, reports on the use of ISSR markers to elucidate variability in induced mutants of Curcuma are rather unknown. ISSR, which was first published by Zietkiewicz et al. (1994), is a kind of simple and quick technique and does not require previous knowledge of the sequence of the genome being tested. Because of some advantages of ISSR such as stability and reproducibility, rich polymorphism, reliability, much larger numbers of fragments per primer, and relatively low cost, they have been widely used for DNA fingerprinting, population genetics, and phylogenetic studies (Zhou et al., 2007). Additionally, ISSR was described as a powerful technique to assess genetic diversity (Aparajita et al., 2008; Liu et al., 2008; Tian et al., 2008) and to detect similarities between and within species (Ghariani et al., 2003). The present study was therefore designed to evaluate the effectiveness of different doses of gamma irradiation in DNA variation induction and to assess the application of ISSR as a tool to identify DNA polymorphism among the mutants, and finally this research aimed at comparing the $C$. alismatifolia varieties in terms of induced DNA variation.

\section{Materials and Methods} (Mivazi et al, 2006); native ornamentals with limited gene pools in a given species (Maluszynski et al., 1995); or plants with long juvenile periods before flowering and seed production (Predieri, 2001). For the past 80 years, mutation induction has been a routine tool for the generation of genetic variation in crop germplasm and has been overwhelmingly used in crop improvement, a strategy that is known as mutation breeding (Oswaldo, 2007). According to the International Atomic Energy Agency Mutant Varieties Database (http://www-mvd.iaea.org), 3200 mutant varieties have been officially released worldwide. Of these, 625 varieties are ornamental and decorative plants. Gamma rays have been most successfully used and new mutant varieties with altered flower color/shape, and

\section{Source of plant materials}

The rhizomes of three $C$. alismatifolia varieties, namely 'Chiang Mai Red' (SK 2051/12), 'Sweet Pink' (SK 2052/12), 'Kimono Pink' (SK 2054/12), and one Curcuma hybrid (C. alismatifolia var. Chiang Mai Pink $\times$ Curcuma sparganifolia) namely 'Doi Tung554' (SK 2053/12), were provided by the Curcuma Nursery (Ubonrat) in Doisaket District, Chiang Mai 50220, Thailand.

\section{Gamma irradiation of $C$. alismatifolia rhizomes}

Irradiation of rhizomes of the C. alismatifolia population was conducted at the Faculty of Science and Technology, University 
Kebangsaan Malaysia, using a Gammacell 220 Excel Irradiator (MDS Nordion, Ottawa, Ontario, Canada). The source of gamma rays was Cobalt $60\left({ }^{60} \mathrm{Co}\right)$. Two hundred forty sprouted rhizomes were acutely irradiated with a total optimum dose of $10 \mathrm{~Gy}(12.8 \mathrm{~s})$ and $20 \mathrm{~Gy}(25.6 \mathrm{~s})$ at a rate of $46.8 \mathrm{~Gy} / \mathrm{min}$. For each variety, 20 rhizomes were treated at each dose and 20 non-irradiated rhizomes were used as controls ( 0 Gy). After irradiation, the rhizomes were planted in $25-\mathrm{cm}$ pots containing growth media consisting of top soil, coco-peat, and rice husk in the ratio of 1:2:1 (recommended ratio by Curcuma nursery). The pots were placed in a greenhouse at University Putra Malaysia. The pots were watered manually to saturation once every $2 \mathrm{~d}$, starting after planting of the bulbs. Malathion ${ }^{\circledR}$ and Benlate ${ }^{\circledR}$ were sprayed weekly to prevent the incidence of unwanted pests and diseases. The soil was fertilized with a $15 \mathrm{~N}-15 \mathrm{P}-15 \mathrm{~K}$ once a month at the rate of $5 \mathrm{~g}$ per pot (Bunya-atichart et al., 2004). The experiment comprising four (variety) $\times$ three (dose) treatments was arranged in a randomized complete block design in five replications with four samples in each replication.

\section{ISSR assay}

Total genomic DNA extraction. Genomic DNA was extracted from fresh and tender leaves of 40 treated and four non-treated samples (in total 44 samples). The genomic DNA was isolated by the modified Cetyltrimethyl Ammonium Bromide method (Taheri et al., 2012).

PCR amplification and product electrophoresis. The primer screening was carried out (for untreated samples) to select polymorphic primers out of 25 ISSR primers. The DNA amplification was carried out in $15-\mu \mathrm{L}$ reaction volumes including deionized water, 2× DreamTaq ${ }^{\text {TM }}$ Green PCR Master Mix (Fermentas, International Inc.) with $1 \mu \mathrm{L}$ of $0.6 \mu \mathrm{M}$ oligodeoxynucleotide primer, and 70 ng. $\mu \mathrm{L}^{-1}$ DNA (Taheri et al., 2012). All reactions were performed in a thermal cycler (Bio-Rad Laboratories, Inc.) for a total of 40 cycles after an initial denaturation of the template DNA at $94{ }^{\circ} \mathrm{C}$ for $3 \mathrm{~min}$. This was followed by 10 cycles of $94^{\circ} \mathrm{C}$ for $40 \mathrm{~s}$, touchdown $1^{\circ}$ decrement for annealing temperature started with $7{ }^{\circ} \mathrm{C}$ above melting temperature for each primer for $30 \mathrm{~s}$, and $72^{\circ} \mathrm{C}$ for $1 \mathrm{~min}$. Then, this was followed by 30 cycles of $95^{\circ} \mathrm{C}$ for $40 \mathrm{~s}$, last annealing temperature for $30 \mathrm{~s}$ (Table 1), and $72{ }^{\circ} \mathrm{C}$ for $1 \mathrm{~min}$ and final extension of $72{ }^{\circ} \mathrm{C}$ for $10 \mathrm{~min}$. Electrophoresis was carried out on $2 \%$ agarose gel with a 100-bp DNA ladder (N3231S, Biolabs, Inc.) in $1 \times$ TBE (Tris/Borate/EDTA) buffer $(\mathrm{pH}=8)$ at $70 \mathrm{~V}$ for 90 min using a Bio-Rad submarine gel electrophoresis unit. The gel was stained with Midori green and visualized under ultraviolet light. Finally, gel photographs were scanned through a Gel Doc System (ChemilImager ${ }^{\mathrm{TM}}$ Gel Doc; Alpha Innotech Corporation, CA).

Data scoring and analysis. The banding pattern for each primer was scored using UVIDOC software and fragment sizes were

Table 1. Intersimple sequence repeat polymorphic primer sequences used for analysis of 44 individuals of C. alismatifolia population with primer melting and annealing temperature.

\begin{tabular}{clccc}
\hline Serial number & Primer & Sequence $\left(5^{\prime}-3^{\prime}\right)$ & $\mathrm{T}_{\mathrm{m}}$ value $\left({ }^{\circ} \mathrm{C}\right)$ & $\mathrm{T}_{\mathrm{a}}$ value $\left({ }^{\circ} \mathrm{C}\right)$ \\
\hline 1 & ISSR807 & (AG)8T & 57.2 & $64-54$ \\
2 & ISSR808 & (AG)8C & 58.9 & $66-56$ \\
3 & ISSR809 & A(GA)7 GG & 58.3 & $65-55$ \\
4 & ISSR810 & (GA)8T & 55.4 & $62-52$ \\
5 & ISSR811 & (GA)8C & 56.6 & $63-53$ \\
6 & ISSR825 & (AC)8T & 61.4 & $68-58$ \\
7 & ISSR826 & (GA)8T & 62.7 & $69-59$ \\
8 & ISSR827 & (AC)8G & 62.7 & $70-60$ \\
9 & ISSR864 & (ATG)6 & 52.9 & $60-50$ \\
10 & ISSR873 & (GACA)4 & 57.8 & $65-55$ \\
11 & RAMP-TAG & T(AG)9 & 57.1 & $64-54$ \\
12 & RAMP-GAG & G(AC)9 & 62.8 & $70-60$ \\
13 & LK7 & CCA(CT)8 & 60.9 & $68-58$ \\
14 & ISSR1-9 & A(GA)7GGT & 60.0 & $67-57$ \\
\hline
\end{tabular}

$\mathrm{T}_{\mathrm{m}}=$ melting temperature $\left({ }^{\circ} \mathrm{C}\right) ; \mathrm{T}_{\mathrm{a}}=$ annealing temperature $\left({ }^{\circ} \mathrm{C}\right)$.

estimated based on a DNA ladder. Amplified products were scored as present (1) or absent (0) from the photographic examination to form a binary matrix (Liu et al., 2006). As a result of dominancy of ISSR markers, it was assumed that each DNA fragment position corresponded to an ISSR locus with two alleles revealed by band absence or presence (Powell et al., 1996). To assess the genetic variation among the $C$. alismatifolia population, the binary matrix data matrix was entered into the Numerical Taxonomy and Multivariate Analysis System (NTSYSpc2.10e; Rohlf, 2002). The genetic similarity for all pairwise comparisons was computed using Jaccard's coefficient. The similarity matrix was used to create the dendrogram using the unweighted paired group method using arithmetic average (UPGMA). The software POPGENE32, Version 1.32 (Yeh et al., 2000), was used to calculate the percentages of polymorphic bands, number of alleles (na), effective number of alleles (ne), gene diversity (h), and Shannon's information index. The average PIC value for dominant markers was calculated following the formula described by $\mathrm{De}$ Riek et al. (2001) PIC $=1-\left[p^{2}+(1-p)^{2}\right]$ where " $p$ " is the frequency of the marker in the data set. PIC for dominant markers is a maximum of 0.5 for " $p$ " $=0.5$.

\section{Results}

\section{Primer screening}

Twenty-five primers were selected for DNA amplification of untreated samples. Of 25 ISSR primers, 14 primers produced clear and repeatable amplicon profiles and they were chosen for fingerprinting of all 44 non-treated and treated samples. A total of 329 scoreable and repeatable fragments were amplified across 44 individuals of the C. alismatifolia populations at the three doses of 0,10 , and 20 Gy (Table 2). The size of fragments ranged from 250 to $1900 \mathrm{bp}$. Three of 14 primers revealed ISSR loci with $100 \%$ polymorphism at all three doses (ISSR810, ISSR873, and RAMP-GAG), whereas ISSR825 and RAMP-TAG showed $100 \%$ polymorphism at $0-\mathrm{Gy}$ and $20-\mathrm{Gy}$ doses, respectively. Other primers detected polymorphic loci from 33\% (ISSR807 and
LK7) to $91.5 \%$ (ISSR825). In the $10-\mathrm{Gy}$ dosage treatment, the number of alleles ranged from four (ISSR807, ISSR827, LK7) to 17 (ISSR873) with an average value of 7.8 per locus. In the 20-Gy treatment, the number of alleles varied from four (ISSR807) to 19 (ISSR873) with an average value of 9.2 per locus, whereas the number of alleles ranged from three (ISSR807 and LK7) to 10 (ISSR825) with an average value of 6.5 in untreated samples.

\section{Genetic variation induced with different doses}

Non-irradiated (0 Gy) individual plants produced 91 bands of which 76 bands were polymorphic, whereas of 109 and 129 of produced bands at 10- and 20-Gy dose levels, 96 and 116 were polymorphic bands, respectively (Fig. 1). Percentage of polymorphic loci for 0,10 , and 20 Gy individual plants were $76.4 \%, 83.7 \%$, and $85.8 \%$, respectively, with an average of $81.9 \%$. The observed number of alleles per locus (na) were 1.76 , 1.84 , and 1.86 for non-treated, $10 \mathrm{~Gy}$, and 20 Gy irradiated samples, respectively, with a mean of 1.8779 . The number of effective alleles per locus (ne) recorded for the three doses ranged from 1.41 to 1.48 with a mean of 1.45. The highest mean Nei's gene diversity (h) was for 20 Gy irradiated samples (0.33), followed by 10 Gy $(0.27)$ and 0 Gy (0.24) with an average of 0.28. Overall genetic variability for the individual plants, represented by Shannon's information index, was moderately low with an average of $0.35,0.38$, and 0.45 at 0,10 , and $20 \mathrm{~Gy}$, respectively. The PIC value per primer ranged from 0.10 (UBC807) to 0.24 (UBC809 and UBC810), 0.11 (UBC807)-0.28 (UBC809), and 0.16 (UBC826)-0.39 (UBC827) with an average value of $0.21,0.21$, and 0.25 per primer at 0,10 , and $20 \mathrm{~Gy}$, respectively.

\section{Cluster analysis}

Jaccard's genetic similarity coefficients indicated a high level of genetic variation among the non-irradiated and irradiated samples and ranged from a minimum of 0.21 to a maximum of 1.0. The UPGMA cluster analysis of the Jaccard's similarity coefficients generated a dendrogram (Fig. 2), which illustrated 
Table 2. Intersimple sequence repeat polymorphic primers, number of polymorphic loci, percentage of polymorphic loci, and estimates of variability across 44 individuals of C. alismatifolia population.

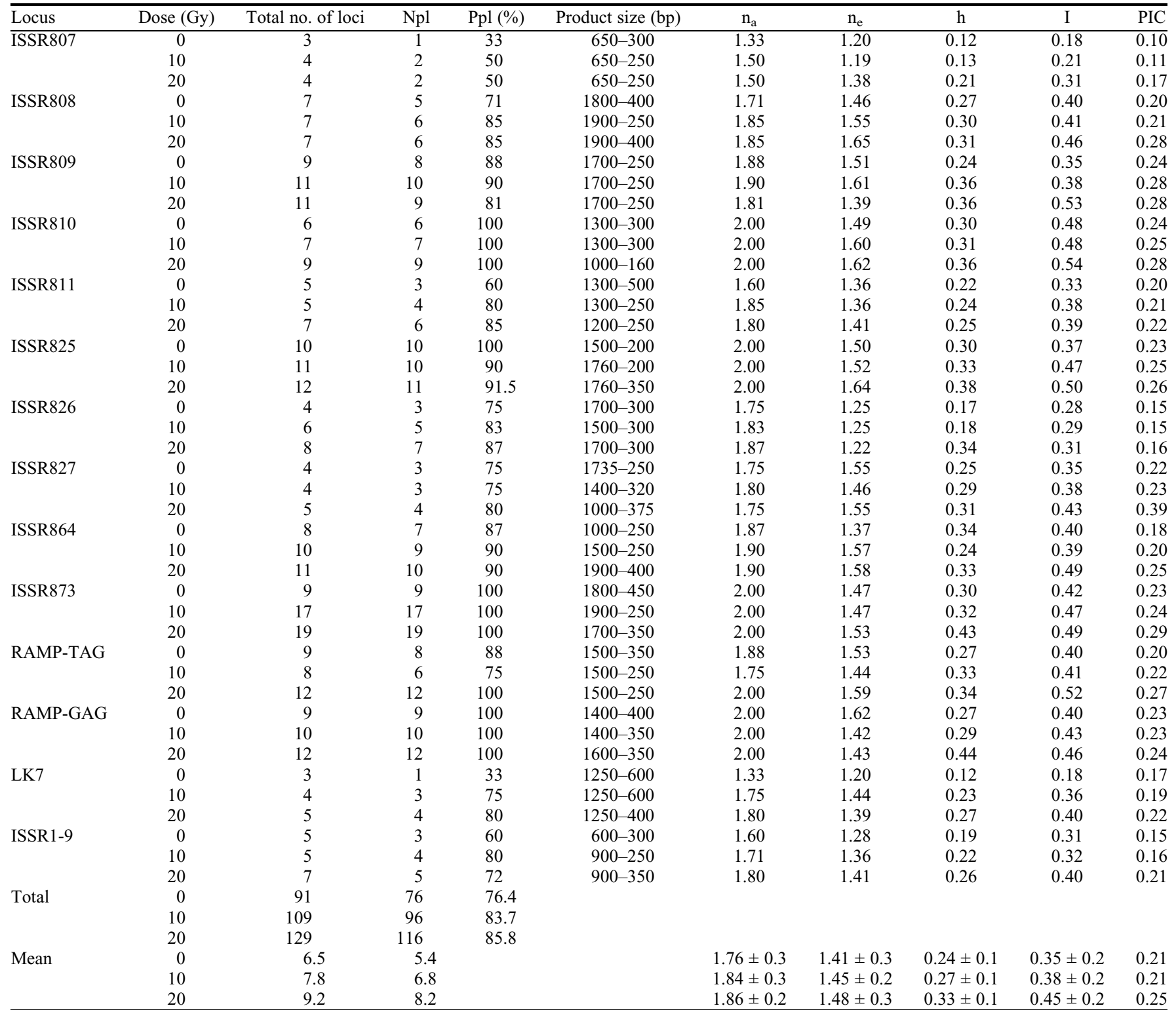

$\mathrm{Npl}=$ number of polymorphic loci; $\mathrm{Ppl}=$ percentage of polymorphic loci; $\mathrm{n}_{\mathrm{a}}=$ observed number of alleles; $\mathrm{n}_{\mathrm{e}}=$ effective number of alleles; h: Nei's $(1973)$ gene diversity; I = Shannon's information index; PIC = polymorphic information content.

the overall genetic relationship among the individuals of the C. alismatifolia population. The analysis showed that 44 C. alismatifolia individual plants fell into seven distinct main clusters at a coefficient level 0.35 . The first main cluster comprised all 10 and 20 Gy-irradiated 'Kimono Pink' individual plants along with SP20-1, whereas the second cluster included all 10 Gy-irradiated 'Sweet Pink' and all 10 Gy irradiated 'Doi Tung' individuals. All 0 and 10 Gy 'Chiang Mai Red' individuals along with non-treated 'Sweet Pink' were assigned to Cluster III. Cluster IV was composed of SP20-2, SP20-3, SP20-4, and SP20-5 individuals. The 20 Gy-irradiated 'Chiang Mai Red' and non-treated 'Doi Tung' samples were assigned to Group V. DT20-1, DT20-2, DT20-3, DT20-4, and DT20-5 were grouped in Cluster VI. Non-treated 'Kimono Pink' individual were the sole member of Cluster VII.

\section{Discussion}

Although the most common use of the ISSR assay is related to genetic diversity, phylogeny, gene tagging, genome mapping, and evolutionary biology studies (Reddy et al., 2002), the method has also been used to detect DNA variation in mutations (Labajová et al., 2011; Mejri et al., 2012). The aim of the present study was to evaluate DNA polymorphism through ISSR markers among nontreated and treated $C$. alismatifolia individual plants. The genetic alternations produced by ionizing radiation are the result of ionization and excitation of the DNA molecules. Induced mutations increase DNA polymorphism and ISSR variation by gene mutations and chromosome breaks (Wolfe and Liston, 1998). However, the polymorphism in genomic DNA was detected by ISSR profiles. In this sense, disappearance of normal bands and appearance of new bands resulted from the plants exposed to different doses of gamma irradiation in comparison with the untreated control. The lost bands in C. alismatifolia plants exposed to gamma irradiation were determined generally as polymerase chain reaction (PCR) products with different molecular weight. This suggests that the DNA damage may be serious in the majority of cells in the plant parts of $C$. alismatifolia exposed to gamma irradiation. The disappearance of normal bands (loss of bands) maybe related to events such as DNA damage (e.g., single and double-strand breaks, modified bases), DNA-protein crosslinks, point mutation, and/or complex chromosomal rearrangements induced by gamma radiation (Atienzar and Jha, 2006). Radiation is one of the best known physical mutagens in which the water molecule is one of its major, direct, and most important targets. Radiation 
A

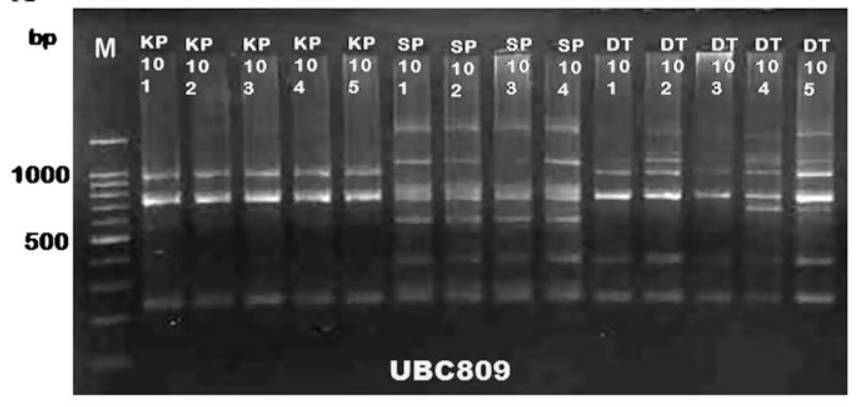

C

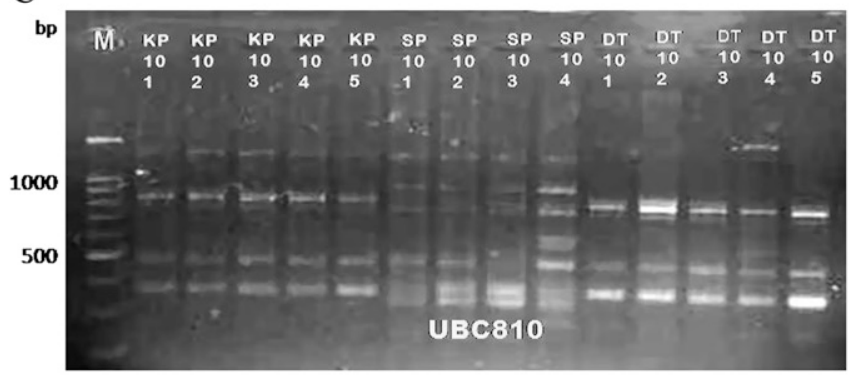

B

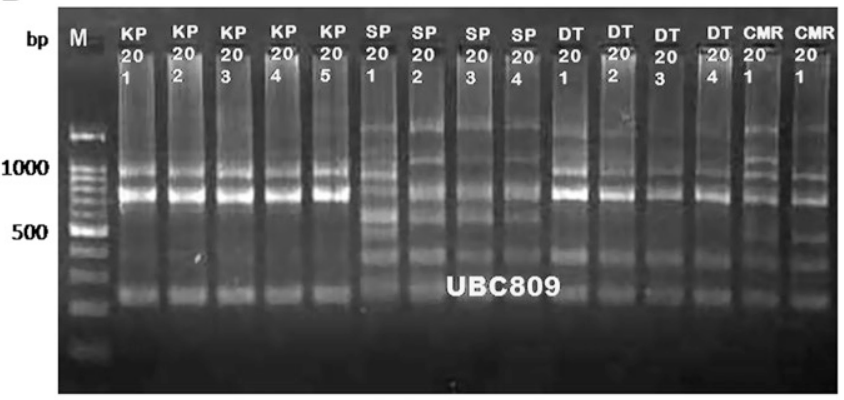

D

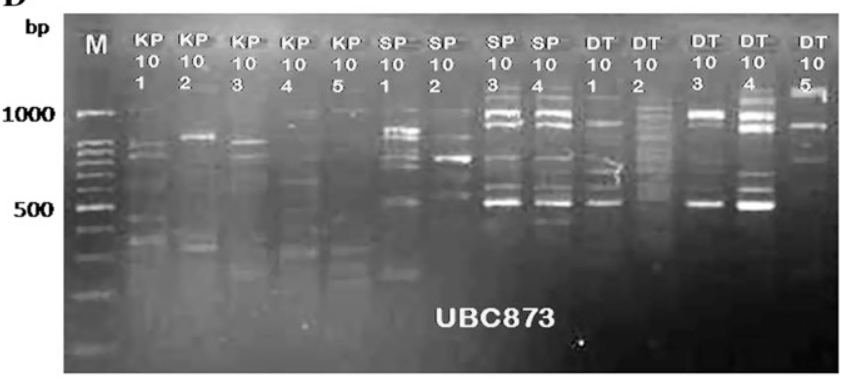

E

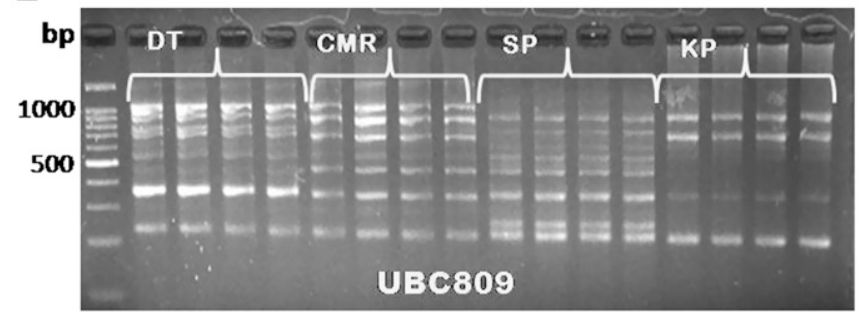

Fig. 1. Polymorphic intersimple sequence repeat (ISSR) marker profiles for 44 individuals of C. alismatifolia population in $2 \%$ agarose gel using primers UBC 809 , UBC810, and UBC 873. M is 100-bp DNA ladder; (A) 10 Gy-irradiated KP, SP, and DT; (B) 20 Gy-irradiated KP, SP, and DT; (C) 10 Gy-irradiated KP, SP, and DT; (D) 10 Gy-irradiated KP, SP, and DT; (E) non-irradiated individuals of C. alismatifolia. KP = Kimono Pink; SP = Sweet Pink; CMR = Chiang Mai Red; DT = Doi Tung.

dissociates the atoms of water molecules $\left(\mathrm{H}_{2} \mathrm{O}\right)$ and produces the primary free radicals $\mathrm{H}^{+}$and $\mathrm{OH}^{-}$. However, in biological tissues, these ionizations are induced all along the path of the radiation and lead to chain reactions, which produce secondary reactive oxygen species (ROS). The most important ROS is $\mathrm{H}_{2} \mathrm{O}_{2}$ (Lee et al., 2009). The $\mathrm{OH}$ radical can react rapidly with various types of macromolecules, including lipids, proteins, and in particular DNA. The oxidation of biomolecules by the radicals damages their structure and biological activity. Thus, genetic alterations occur on the DNA molecules. When Taq DNA polymerase encounters a DNA adduct, there are a number of possible outcomes including blockage, bypass, and the possible dissociation of the enzyme/adduct complex, which will cause the loss of bands (Atienzar and Jha, 2006). Appearance of extra bands was also detected in ISSR profiles. New PCR amplification products may reveal a change in some oligonucleotide priming sites as a result of mutations [new annealing event(s)], large deletions (bringing the preexisting annealing site closer), and/or homologous recombinations (Atienzar et al., 1999). Atienzar et al. (2000) reported that mutations can only be responsible for the appearance of new bands if they occur at the same locus in a sufficient number of cells (a minimum of $10 \%$ of mutations may be required for a new PCR product to be visible in agarose gel) to be amplified by PCR. The new bands could be attributed to mutation, whereas the disappearance of bands could be attributed to DNA damage (Atienzar and Jha, 2006), both of them resulting in the generation of DNA polymorphism in gamma ray-treated plants.

All primers tested revealed $76.4 \%, 83.7 \%$, and $85.8 \%$ polymorphism among the 44 studied individuals suggesting that the 20Gy dose of gamma radiation induced more DNA variation in ISSR profiles of irradiated plants in comparison with the 10-Gy dose. Taheri et al. (2012) observed 77\% polymorphism for 16 primers (UBC811, UBC812, UBC 818, UBC826, UBC834, UBC835, UBC841, UBC842, UBC847, UBC848, UBC 850, UBC880, $\mathrm{I}_{1}, \mathrm{I}_{2}, \mathrm{I}_{3}, \mathrm{I}_{7}$ ) across four varieties and one hybrid of Curcuma alismatifolia. Polymorphism of amplified fragments is caused by: 1) base substitution or deletion in the priming sites; 2 ) insertions that render priming sites too distant to support amplification; or 3) insertions or deletions that change the size of the amplified fragment (Chopra, 2005). The overall Shannon's information index was higher at the 20-Gy dose
$(I=0.45)$, indicating that the higher dose induced greater genetic variation among the C. alismatifolia population than the 10-Gy dose $(\mathrm{I}=0.38)$. The Shannon's information index in our study, even at the 20-Gy dose, was lower than that reported in previous studies using ISSR $(\mathrm{I}=0.51)$ and RAPD $(\mathrm{I}=0.53)$ (Das et al., 2011). However, its average was higher than that previously reported for ISSR $(I=0.43)$ (Taheri et al., 2012) and AFLP markers ( $\mathrm{I}=0.38$ ) (Das et al., 2011), indicating a relatively greater genetic variation induced in the studied C. alismatifolia population. The higher value of Shannon's information index represents the effectiveness of ISSR markers loci to reveal the DNA variation. To evaluate the distribution of genetic variation in the population, Nei's (1973) gene diversity statistics was used. As a whole, the selected ISSR primers generated an average of 9.2 alleles with the 20-Gy irradiation dose. On a perlocus basis, these numbers were much higher than the average of one to six alleles per locus for the various ISSR loci reported by Das et al. (2011). The average number of alleles per locus obtained in the present study was also higher than that reported in previous studies using ISSR (1.48) (Taheri et al., 2012); however, the average number of 


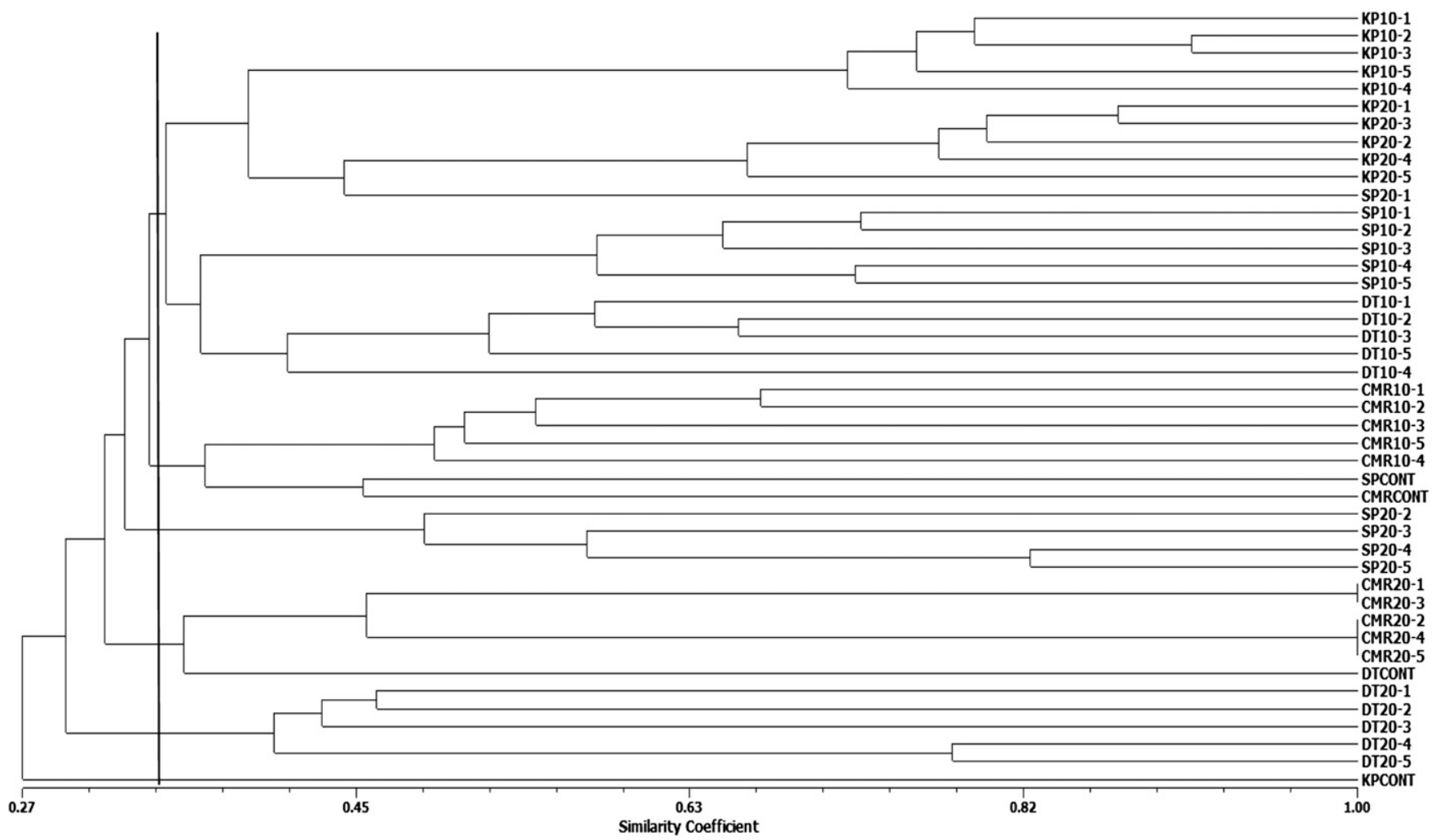

Fig. 2. Dendrogram representing the genetic variability among 44 irradiated and non-irradiated individuals of $C$. alismatifolia population. CMR $=$ Chiang Mai Red; DT = Doi Tung 554; SP = Sweet Pink; Kp = Kimono Pink.

alleles per locus was lower than that reported Syamkumar and Sasikumar (2007) who observed an average of 11.3 alleles per locus over eight ISSR loci among 14 species of Curcuma or from other types of markers such as isozymes (3.37) (Paisooksantivatana et al., 2001). The mean PIC value obtained in the present study (0.22) was lower than that reported by Das et al. (2011) using ISSR $(0.38)$ for studying of intra- and interspecific genetic diversity of nine Curcuma species. The mean PIC for 20 Gy $(\mathrm{PIC}=0.25)$ irradiated plants was higher than that obtained at 0 - and 10 -Gy $(\mathrm{PIC}=0.21)$ doses, which proved the viewpoint that the $20-\mathrm{Gy}$ dose induced more DNA variation in the $C$. alismatifolia population. The PIC value provides an estimate of the discriminatory power of a marker by taking into account not only the number of alleles at a locus, but also the relative frequencies of these alleles (Shiran et al., 2007).

The dendrogram constructed based on UPGMA analysis of ISSR data is one of the most effective methods in numerical computation (Zhiyi and Haowen, 2004). Hence, it was used to observe the genetic relationship among the 44 individuals of the C. alismatifolia population. According to the dendrogram constructed using ISSR markers, the grouping pattern of the 'Chiang Mai Red' population was different from the other three varieties, and the 0 and 10 Gy individuals were assigned to the same group. However, in the other three varieties, the control individuals were assigned to different groups from the mutants (10 Gy and $20 \mathrm{~Gy}$ ) showing greater distance between the mutants and controls. Jaccard's similarity coefficient in the 'Chiang Mai Red' variety ranged from a minimum of 0.30 (CMR20-1 and CMR20-3) to a maximum of 0.44 (CMR10-1). In a variety of 'Doi Tung 554', greater similarity (0.40) was observed among DT10-3 and control individuals, whereas DT20-1 showed the most genetic distance from the controls (0.27). The 'Sweet Pink' variety SP20-1 showed the least genetic similarity $(0.31)$ with the controls. Lastly, among 'Kimono Pink' individual plants, the 20 Gy-irradiated individuals showed more genetic distance (0.22) compared with the 10 Gy $(0.28)$ -irradiated individuals. These results showed that the 20-Gy dose of radiation induced more genetic variation in the C. alismatifolia population. These results also showed that the range of genetic variation $(0.27$ to 0.4$)$ among individuals of the 'Doi Tung' variety was greater than that observed in the other three varieties. The higher variation in 'Doi Tung' could be the result of being a hybrid between $C$. alismatifolia var. 'Chiang Mai Pink' $(2 \mathrm{n}=32)$ and $C$. sparganifolia $(2 \mathrm{n}=$ $32)$. Hence, gamma irradiation induced more DNA variation among the 'Doi Tung 554' population. In fact, hybridization may be viewed as an "invasion of the genome" from a genetic viewpoint (Mallet, 2005), which promotes genetic evolution, and the rearrangement of parental species genomes may widen the adaptive range for survival (heterosis). Through this process, life becomes more adaptive and diversified, especially in plants (Ansell et al., 2007; Erickson and
Fenster, 2006; Smith and Baum, 2006). Several studies have shown that novel alleles might evolve in the context of hybridization (Schilthuizen et al., 1999; Smith et al., 2003), which are rare, even absent, in the parental populations.

\section{Conclusion}

This is the first report on molecular characterization of induced mutagenesis through gamma irradiation using ISSR marker analysis in Curcuma alismatifolia. For the purpose of plant breeding programs, mutagenic treatments with low physiological effects and strong genetic effects are desirable. Hence, the use of gamma irradiation at a dose range of 10 to 20 Gy demonstrated induction of genetic variation in C. alismatifolia, and in particular the 20-Gy dose was effective in influencing the $C$. alismatifolia genome. Our data support the view that the ISSR assay offers great promise, especially for the detection of DNA polymorphism induced by gamma radiation. Whereas new technologies and assays are being developed to detect DNA variation in mutants, the ISSR-based technique offers great promise for the future and would continue to complement other new techniques in population genetics studies. It is shown that ISSRs with similar properties to RAPDs can make substantial contribution to DNA variation analysis. However, with high repeatability of ISSRs (compared with RAPDs), they may find further use, especially with organisms that do not have adequate genomic information for locus-specific 
genotyping. The results of the present study clearly demonstrated that the 'Doi Tung 554' variety with a higher amount of genetic variation was more affected by the gamma rays compared with the other three varieties. The ISSR marker generated genetic variation among control and gamma ray-treated populations will be useful in distinguishing plants with differences in morphological characteristics.

\section{Literature Cited}

Ahloowalia, B.S. and M. Maluszynski. 2001. Induced mutations-A new paradigm in plant breeding. Euphytica 118:167-173.

Ahloowalia, B.S., M. Maluszynski, and K. Nichterlein. 2004. Global impact of mutation-derived varieties. Euphytica 135:187-204.

Ansell, S.W., H. Schneider, N. Pedersen, M. Grundmann, S.J. Russell, and J.C. Vogel. 2007. Recombination diversifies chloroplast trnF pseudogenes in Arabidopsis lyrata. J. Evol. Biol. 20:2400-2411.

Aparajita, S., S.K. Senapati, and G.R. Rout. 2008. Identification and genetic relationships among nine Albizzia species based on morphological and molecular markers. Plant Biosyst. 142:30-39.

Atienzar, F.A., M. Conradi, A.J. Evenden, A.N. Jha, and M.H. Depledge. 1999. Qualitative assessment of genotoxicity using random amplified polymorphic DNA: Comparison of genomic template stability with key fitness parameter in Daphnia magna exposed to benzo [a] pyrene. Environ. Toxicol. Chem. 18:2275-2282.

Atienzar, F.A., B. Cordi, M.E. Donkin, A.J. Evenden, A.N. Jha, and M.H. Depledge. 2000. Comparison of ultraviolet-induced genotoxicity detected by random amplified polymorphic DNA with chlorophyll fluorescence and growth in a marine macroalgae, Palmaria palmate. Aquat. Toxicol. 50:1-12.

Atienzar, F.A. and A.N. Jha. 2006. The random amplified polymorphic DNA (RAPD) assay and related techniques applied to genotoxicity and carcinogenesis studies: A critical review. Mutat. Res. 613:76-102.

Broertjes, C., S. Roest, and G.S. Bokelmann. 1976. Mutation breeding of Chrysanthemum morifolium Ram. using in vivo and in vitro adventitious bud techniques. Euphytica 25:11-19.

Bunya-atichart, K., K. Saichol, and W.G. van Doorn. 2004. Postharvest physiology of Curcuma alismatifolia flowers. Postharvest Biol. Technol. 34:219-226.

Chopra, V.L. 2005. Mutagenesis: Investigating the process and processing the outcome for crop improvement. Curr. Sci. 89:353-359.

Das, A., V. Kesari, V.M. Satyanarayana, A. Parida, and L. Rangan. 2011. Genetic relationship of Curcuma species from northeast India using PCR-based markers. Mol. Biotechnol 49:65-76.

De Riek, J., E. Calsyn, I. Everaert, E. Van Bockstaele, and M. De Loose. 2001. AFLP based alternatives for the assessment of distinctness, uniformity and stability of sugar beet varieties. Theor. Appl. Genet. 103:1254-1265.

Erickson, D.L. and C.B. Fenster. 2006. Intraspecific hybridization and the recovery of fitness in the native legume Chamaecrista fasciculata. Evolution 60:225-233.

Ghariani, S., N. Trifi-Farah, M. Chakroun, S. Marghali, and M. Marrakchi. 2003. Genetic diversity in Tunisian perennial ryegrass revealed by ISSR markers. Genet. Resources Crop Evol. 50:809-815.

Kumar, S., K.V. Prasad, and M.L. Choudhary. 2006. Detection of genetic variability among chrysanthemum radiomutants using RAPD markers. Curr. Sci. 90:1108-1113.

Labajová, M., S. Senková, J. Žiarovská, K. Ražná, M. Bežo, V. Štefúnová, and L. Zeleňáková. 2011. The potential of ISSR markers in Amaranth gamma-radiance mutants genotyping. J. Microbiol. Biotechnol. and Food Sci. (JMBFS) 1:507-521.

Lee, M.H., Y.R. Moon, B.Y. Chung, J.S. Kim, K.S. Lee, J.Y. Cho, and J.H. Kim. 2009. Practical use of chemical probes for reactive oxygen species produced in biological systems by gamma irradiation. Radiat. Phys. Chem. 78:323-327.

Liu, J.J., A.K.M. Ekramoddoullah, R. Hunt, and A. Zamani. 2006. Identification and characterization of RAPD markers linked to a major gene (Cr2) for resistance to Cronartiumribicola (Fish.) in Pinusmonticola (D. Don.). Phytopathology 96:395-399.

Liu, L.W., L.P. Zhao, Y.Q. Gong, M.X. Wang, L.M. Chen, J.L. Yang, Y. Wang, F.M. Yu, and L.Z. Wang. 2008. DNA fingerprinting and genetic diversity analysis of late-bolting radish cultivars with RAPD, ISSR and SRAP markers. Sci. Hort. 116:240-247.

Mallet, J. 2005. Hybridization as an invasion of the genome. Trends Ecol. Evol. 20:229-237.

Maluszynski, M., B.S. Ahloowalia, and B. Sigurbjornsson. 1995. Application of in vivo and in vitro mutation techniques for crop improvement. Euphytica 85:303-315.

Mejri, S., Y. Mabrouk, M. Voisin, P. Delavault, P. Simier, M. Saidi, and O. Belhadj. 2012. Variation in quantitative characters of faba bean after seed irradiation and associated molecular changes. Afr. J. Biotechnol. 11:8383-8390.

Miyazaki, K., K. Suzuki, K. Iwaki, T. Kusumi, T. Abe, S. Yoshida, and H. Fukui. 2006. Flower pigment mutations induced by heavy ion beam irradiation in an interspecific hybrid of Torenia. Plant Biotechnol. 23:163-167.

Nei, M. 1973. Analysis of gene diversity in subdivided populations. Proc. Natl. Acad. Sci. USA 70:3321-3323.

Oswaldo, W. 2007. Gamma rays and carbon ion beam irradiation for mutation induction to breed banana (Musa spp.) especially on response to black Sigatoka disease. PhD diss., University of Tsukoba, Tsukoba, Japan.

Paisooksantivatana, Y., S. Kako, and H. Seko. 2001. Genetic diversity of Curcuma alismatifolia Gagnep. (Zingiberaceae) in Thailand as revealed allozyme polymorphism. Genet. Resources Crop Evol. 48:459-465.

Panda, M.K., S. Mohanty, E. Subudhi, L. Acharya, and S. Nayak. 2007. Assessment of genetic stability of micropropagated plants of Curcuma L. by cytophotometery and RAPD analysis. Intl. J. Integr. Biol. 1:189-195.

Powell, W., M. Morgante, M. Hanafey, J. Vogel, S. Tingey, and A. Rafalski. 1996. The comparison of RFLP RAPD AFLP SSR (microsatellite) markers for germplasm analysis. Mol. Breed. 2:225-238.

Prathepha, P. 2000. Screening of random primer to evaluate DNA diversity in Thai Curcuma using random amplified polymorphic DNAs. Songklanakarin J. Sci. Technol. 22:7-13.

Predieri, S. 2001. Mutation induction and tissue culture in improving fruits.. Plant Cell Tiss. Org. Cult. 64:185-210.

Reddy, M.P., N. Sarla, and E.A. Siddiq. 2002. Inter simple sequence repeat (ISSR) polymorphism and its application in plant breeding. Euphytica 128:9-17.

Rohlf, F.J. 2002. NTSYS-pc: Numerical Taxonomy System. Version 2.1. Exeter Publishing, Ltd., Setauket, NY.
Schilthuizen, M., R.F. Hoekstra, and E. Gittenberger. 1999. Selective increase of a rare haplotype in a land snail hybrid zone. Proc. Royal Soc. London Ser. B-Biol. Sci. 266:2181-2185.

Shiran, B., N. Amirbakhtiar, S. Kiani, S.H. Mohammadi, B.E. Sayed-Tabatabaei, and H. Moradi. 2007. Molecular characterization and genetic relationship among almond cultivars assessed by RAPD and SSR markers. Sci. Hort. 111:280-292.

Shu, Q.Y. and P.J.L. Lagoda. 2007. Mutation techniques for gene discovery and crop improvement. China Academic J. Mole. Plant Breed. 5:193-195.

Sigrist, M.S., J.B. Pinheiro, J.A. AzevedoFilho, and M.I . Zucchi. 2011. Genetic diversity of turmeric germplasm (Curcuma longa; Zingiberaceae) identified by microsatellite markers. Genet. Mol. Res. 10:419-428.

Siju, S., K. Dhanya, S. Syamkumar, T.E. Sheeja, B. Sasikumar, A.I. Bhat, and V.A. Parthasarathy. 2010. Development, characterization and utilization of genomic microsatellite markers in turmeric (Curcuma longa L.). Biochem. Syst. Ecol. 38:641-646.

Singh, S., M.K. Panda, and S. Nayak. 2012. Evaluation of genetic diversity in turmeric (C. long) using RAPD and ISSR markers. Ind. Crops Prod. 37:284-291.

Smith, P.F., A. Konings, and I. Kornfield. 2003. Hybrid origin of a cichlid population in Lake Malawi: Implications for genetic variation and species diversity. Mol. Ecol. 12:2497-2504.

Smith, S.D. and D.A. Baum. 2006. Phylogenetics of the florally diverse Andean clade Iochrominae (Solanaceae). Amer. J. Bot. 93:1140-1153.

Syamkumar, S. and B. Sasikumar. 2007. Molecular marker based genetic diversity analysis of $\mathrm{Cur}$ cuma species from India. Sci. Hort. 112:235-241.

Taheri, S., T.L. Abdullah, N.A.P. Abdullah, and Z. Ahmad. 2012. Genetic relationships among five varieties of Curcuma alismatifolia (Zingiberaceae) based on ISSR markers. Genet. Mol. Res. 11:3069-3076.

Tian, H.L., J.H. Xue, J. Wen, G. Mitchell, and S-L. Zhou. 2008. Genetic diversity and relationships of lotus (Nelumbo) cultivars based on allozyme and ISSR markers. Sci. Hort. 116:421-429.

Wolfe, A.D. and A. Liston. 1998. Contributions of PCR-based methods to plant systematics and evolutionary biology, p. 43-86. In: Soltis, P.S., D.E. Soltis, and J.J. Doyle (eds.). Molecular systematics of plants: DNA sequencing. Kluwer, New York, NY

Yeh, F.C., R.C. Yang, T.B.J. Boyle, Z.H. Ye, and J.X. Mao. 2000. Popgen ver. 1.32: The userfriendly shareware for population genetic analysis. Molecular Biology and Biotechnology Center, University of Alberta, Alberta, Canada

Zalewska, M. and M. Jerzy. 1997. Mutation spectrum in Dendranthema grandiflora Tzvelev after in vivo and in vitro regeneration ofplants from irradiated leaves. Acta Hort. 447:615-618.

Zhiyi, R. and Y. Haowen. 2004. A method for genotoxicity detection using random amplified polymorphism DNA with Daniorerio. Ecotoxicol. Environ. Saf. 58:96-103.

Zhou, Y.Q., W.J. Gao, H.Y. Duan, F. Wang, and F. Gu. 2007. Assessment of genetic diversity of Rehmanniaglutinosa Libosch based on ISSR markers. Genet. Mol. Biol. 8:141-149.

Ziekiewicz, E., A. Rafalski, and D. Labuda. 1994. Genome fingerprinting by simple sequence repeat (SSR) anchored polymerase chain reaction amplification. Genome 20:176-183.

Zietkiewicz, E., A. Fafalski, and D. Labuda. 1994 Genome fingerprinting by simple sequence repeat (SSR)-anchored polymerase chain reaction amplification. Genomics 20:176-183. 